\title{
Next-generation sequencing for D47N mutation in Cx50 analysis associated with autosomal dominant congenital cataract in a six-generation Chinese family
}

Chao Shen ${ }^{1+}$, Jingbing Wang ${ }^{1+}$, Xiaotang Wu' ${ }^{1}$, Fuchao Wang ${ }^{1}$, Yang Liu², Xiaoying Guo ${ }^{1}$, Lina Zhang ${ }^{1}$, Yanfei Cao ${ }^{1}$, Xiuhua $\mathrm{CaO}^{1}$ and Hongxing $\mathrm{Ma}^{1 *}$

\begin{abstract}
Background: Congenital cataract is the most frequent cause of blindness during infancy or early childhood. To date, more than 40 loci associated with congenital cataract have been identified, including at least 26 genes on different chromosomes associated with inherited cataract. This present study aimed to identify the genetic mutation in a six-generation Chinese family affected with congenital cataract.

Methods: A detailed six-generation Chinese cataract family history and clinical data of the family members were recorded. A total of 27 family members, including 14 affected and 13 unaffected individuals were recruited. Whole exome sequencing was performed to determine the disease-causing mutation. Sanger sequencing was used to confirm the results.

Results: A known missense mutation, c. 139G > A (p. D47N), in Cx50 was identified. This mutation co-segregated with all affected individuals and was not observed in the unaffected family members or in 100 unrelated controls. The homology modeling showed that the structure of the mutant protein was different with that wild-type Cx50.

Conclusions: The missense mutation C.139G > A in GJA8 gene is associated with autosomal dominant congenital cataract in a six-generation Chinese family. The result of this present study provides further evidence that the $p$. D47N mutation in CX50 is a hot-spot mutation.
\end{abstract}

Keywords: Congenital cataract, GJA8, Whole exome sequencing, Next-generation sequencing

\section{Background}

Congenital cataract is the most frequent cause of blindness during infancy or early childhood, with an occurrence of 1-15/10,000 live births worldwide [1, 2]. It explains for $10 \%-30 \%$ of childhood blindness [3]. Congenital cataract is characterized by the presence of an opacification of the lens at birth or during babyhood. On the basis of morphology, congenital cataract can be classified into several subtypes, including nuclear, sutural, polar, cortical cataract, etc. [4]. Congenital cataract pathogenesis involves

\footnotetext{
* Correspondence: mahongxing@hotmail.com

${ }^{\dagger}$ Equal contributors

'Department of Clinical Diagnosis, General Hospital of Daqing Oil Field,

Daqing, Heilongjiang Province, People's Republic of China

Full list of author information is available at the end of the article
}

several distinct reasons including gene defects, chromosomal abnormalities, metabolic disorders, and infections during embryogenesis. Approximately half of congenital cataracts are inherited [3]. Though autosomal recessive and X-linked inheritances have been reported, inheritance is mainly autosomal dominant [5]. Up to date, over 40 loci associated with congenital cataract have been confirmed, including no less than 26 genes on different chromosomes related to congenital cataract $[6,7]$. Among these mutant genes, the connexin genes and crystallin genes are the most widespread. Briefly, half of the mutations were discovered in the crystalline genes, such as alpha crystallins, beta crystallins and gamma crytallins, and approximately $25 \%$ involve mutations in membrane transport genes, such as connexin proteins $(C x 43, C x 46$, and $C x 50)$ [5-14]. 
In current study, we utilized next-generation sequencing of whole exome to investigate genetic defects in a Chinese pedigree with congenital cataract.

\section{Methods}

Subject recruitment and DNA sampling

A six-generation Chinese cataract family was examined at the General Hospital of Daqing Oil Field, Heilongjiang province, China. Pedigree medical history was taken directly by interviewing the family members. A total of 27 family members, including 14 affected (III12, IV11, IV28, IV30, IV39, IV72, IV73, V9, V11, V27, V28, VI3, VI9, and VI15) and 13 unaffected individuals (IV40, IV68, IV69, IV70, IV71, IV74, V10, V14, V19, V42, V57, V62, VI13) were recruited (Fig. 1). Ethical approval for current research was obtained from the ethics committee of General Hospital of Daqing Oil Field and the study was conducted according to the Declaration of Helsinki of the World Medical Association. All members recruited in this study underwent ophthalmologic examinations, including slit lamp ophthalmoscopy, biometry, visual acuity, and fundus examination. In addition, 100 unrelated healthy subjects without cataracts were also recruited from General Hospital of Daqing Oil Field.
DNA samples were extracted using the QIAamp DNA Blood Midi Kit (Qiagen, Hilden, Germany) from peripheral blood.

\section{Exome sequencing}

Ten patients (III12, IV11, IV28, IV30, IV73, V9, V27, VI3, VI9 and VI15) and one unaffected member of the family (IV40) were selected for exome sequencing. The whole exome-enriched library was built using NimbleGen SeqCap EZ Exome $64 \mathrm{Mb}$ solution-based SeqCap EZ capture reagents, and solution hybridization exome capture was conducted in according with the manufacturer's protocol. Exome sequencing was taken by using an Illumina HiSeq2000 sequencer.

\section{Short-read alignment, variant calling and annotation}

Low quality reads and PCR duplicates with $>5$ unknown bases were eliminated [15], for insertion/deletion (indel) and single nucleotide polymorphism (SNP), respectively. Aligning between read and the National Center for Biotechnology Information human reference genome (hg 19) were performed by sequencing reads were aligned to using Burrows-Wheeler Aligner (BWA) [15] and Short Oligonucleotide Analysis Package (SOAP3) tools [16]. Indels were validated according to the alignment result with the Genome Analysis Toolkit (GATK), and SNP

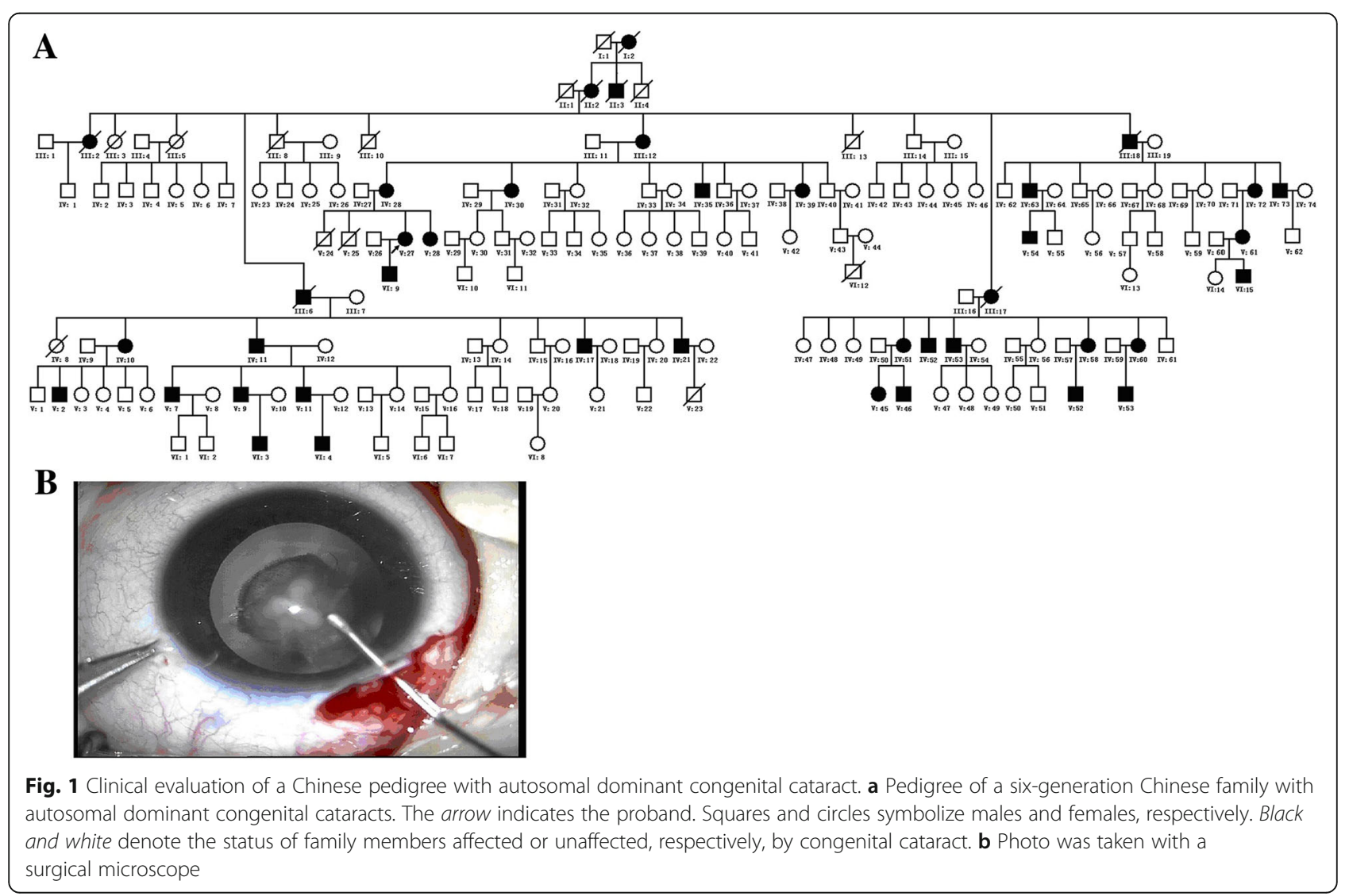


calling was performed with Short Oligonucleotide Analysis Package (SOAPsnp). Variants were annotated using ANNOVAR tool.

\section{Validation of mutation by Sanger sequencing}

Sanger sequencing was used to validate the variants identified by exome sequencing. Specific primers were designed by Primer Premier 3.0 software for the target region. Genomic DNA from participants and 100 normal controls was analyzed.

Genomic DNA samples were amplified with the forward primer (5' - GCAGATCATCTTCGTCTCCA-3') and the reverse primer( $5^{\prime}$ - GGCCACAGACAACATGAACA-3'). The following program was used: $95^{\circ} \mathrm{C}$ for 3 min (1 cycle); $95{ }^{\circ} \mathrm{C}$ for $30 \mathrm{~s}, 60^{\circ} \mathrm{C}$ for $30 \mathrm{~s}, 72{ }^{\circ} \mathrm{C}$ for $30 \mathrm{~s}(30$ cycles); $72{ }^{\circ} \mathrm{C}$ for $10 \mathrm{~min}(1$ cycle).

\section{Bioinformatics analysis}

The effects of wild-type amino acid sequences with the p. D47N mutant of $C x 50$ on the secondary structure were performed using Antheprot 2000 software (version 6.6.5, IBCP, Lypn, France). The solved structure of gap junction protein beta 2(Cx26) was taken as template (Protein Data Bank No.2ZW3). The model structure of homomeric wild-type and the mutant of GJA8 were modelled by Swiss-Model Server [17]. In addition, the possible functional effect of the amino acid change was predicted by PolyPhen- 2 and SIFT.

\section{Results}

\section{Clinical evaluations}

Among 171 members in this six-generation Chinese family, affected individuals account for $23.39 \%$ (Fig. 1). All affect individuals in the pedigree had bilateral cataracts. Autosomal dominant inheritance mode of the congenital cataract was ascertained by the presence of affected individuals in each generation of the family, and male-to-male transmission. The proband's son (VI 9) had been diagnosed with cataracts when he was 15 months old. Slit-lamp examination of his left eye showed perinuclear cataract.

\section{Identification of Cx50 mutation}

Whole exome sequencing was performed on genomic DNA from nine patients of congenital cataract family (III12, IV11, IV28, IV30, IV73, V9, V27, VI3, VI9 and VI15) and one unaffected individual (IV40) though nextgeneration sequencing technology. As demonstrated in Table 1, we obtained at least 64.06 million reads that mapped to targeted exome regions; more than $99.49 \%$ of the target region was covered. The mean depth of the target exome region was $180.98 \times, 191.56 \times, 191.23 \times$, $155.43 \times, 184.67 \times, 197.75 \times, 203.48 \times, 160.48 \times, 167.92 \times$, $155.12 \times$ and $187.92 \times$, respectively. The raw Indel/SNP sequencing data are shown in Table 2 . To help identify candidate mutations, untranslated regions, variants falling within intergenic, synonymous substitutions, intronic were excluded. Then the remaining variants were filtered out in at least four public genetic variant databases, including 1000 Genomes, dbSNP, HapMap and YH. Variants with an allele frequency $>0.5 \%$ were rejected. Variants shared by 10 patients and absent from 1 unaffected individual were analyzed.

After filtering and samples comparison, one heterozygous change was confirmed in all affected individuals in congenital cataract family, G > A, at position 139 (c.139 G > A) in exon 2 of GJA8 (Cx50). This change led to the substitution of aspartic acid by asparagine at position 47 (p. D47N). This mutation was further confirmed by Sanger sequencing (Fig. 2). The D47N substitution co-segregated with all 14 affected individuals, while it was not found in the unaffected family members or in the 100 healthy controls.

\section{Bioinformatics analysis}

The potential structure and function impact of the D47N mutation was predicted to affect protein function with a score of 0.00 , and could probably be damaging with a score of 1.0 by SIFT and PolyPhen-2, respectively. As shown in Fig. 3, the secondary structure of mutant Cx50 protein was different with wild type. The results stated clearly that the wild-type sheet in $\mathrm{COOH}$ - terminal portion is likely missing in the D47N mutant. Took the structure of $\mathrm{Cx}-26$ as template, the model structure of the mutant $\mathrm{Cx} 50$ have distinct changes (Fig. 4). There are additional helix (red arrow) and shortened sheet (green arrow) in the D47N mutant.

\section{Discussion}

In the current study, we confirmed a missense mutation c. 139 G > A in Cx50 (GJA8) in a six-generation Chinese pedigree with congenital cataract. This mutation resulted in an asparagine substitution for aspartic at amino acid residue $47(\mathrm{D} 47 \mathrm{~N})$.

Cataracts are defined as opacification of the normally transparent crystalline lens, and are the leading cause of vision loss in the world. Congenital cataract is a type of cataract that emerges at birth or during early childhood $[5,18]$. The abnormality of lens can interfere with normal development of eyes $[5,19]$. Congenital cataracts can be inherited or familial, either as an isolated lens phenotype or as part of a genetic/metabolic disorder, commonly with full penetrance and autosomal dominant transmission [19]. Genetic factors play an important role in congenital cataract [20]. Gene mutations that affecting the lens development during embryonic period are considered to be the main cause [18]. Up to now, more than 39 genes and loci have been confirmed to be involved in 


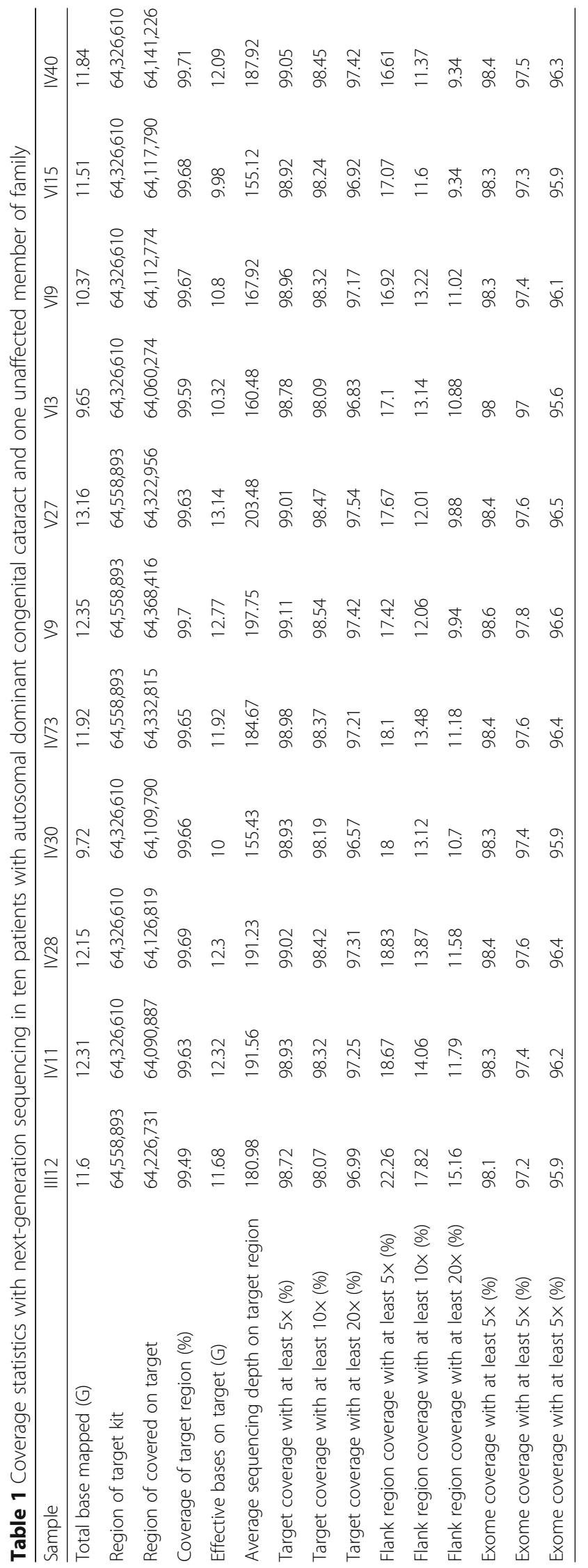


Table 2 Variations identified by whole exome sequencing

\begin{tabular}{|c|c|c|c|c|c|c|c|c|c|c|c|}
\hline Mutation type & || $\mid 12$ & IV11 & IV28 & IV30 & IV73 & V9 & V27 & $\mathrm{VI3}$ & $\mathrm{V} 19$ & VI15 & IV40 \\
\hline \multicolumn{12}{|l|}{ Indel analysis } \\
\hline Total & 15,930 & 15,690 & 15,489 & 13,623 & 15,448 & 15,678 & 18,613 & 14,028 & 14,873 & 14,520 & 15,657 \\
\hline 1000genome and dbsnp & 6813 & 6707 & 6678 & 6153 & 6663 & 6561 & 8340 & 6123 & 6324 & 6375 & 6586 \\
\hline 1000genome specific & 151 & 134 & 128 & 132 & 131 & 143 & 170 & 154 & 129 & 128 & 122 \\
\hline dbSNP specific & 4846 & 4570 & 4462 & 3853 & 4544 & 4448 & 5594 & 4036 & 4406 & 4324 & 4559 \\
\hline dbSNP rate & $73.19 \%$ & $71.87 \%$ & $71.92 \%$ & $73.45 \%$ & $72.55 \%$ & $70.22 \%$ & $74.86 \%$ & $72.42 \%$ & $72.14 \%$ & $73.68 \%$ & $71.18 \%$ \\
\hline Novel & 4120 & 4279 & 4221 & 3485 & 4110 & 4526 & 4509 & 3715 & 4014 & 3693 & 4390 \\
\hline Homozygous & 4857 & 4935 & 4803 & 4405 & 4612 & 4448 & 3181 & 4304 & 4534 & 4601 & 4686 \\
\hline Heterozygous & 11,073 & 10,755 & 10,686 & 9218 & 10,836 & 11,230 & 15,432 & 9724 & 10,339 & 9919 & 10,971 \\
\hline Frameshift & 374 & 413 & 394 & 394 & 406 & 458 & 423 & 392 & 417 & 387 & 397 \\
\hline Non-frameshift Insertion & 158 & 180 & 189 & 153 & 181 & 208 & 195 & 173 & 189 & 164 & 169 \\
\hline Non-frameshift Deletion & 61 & 62 & 63 & 67 & 66 & 81 & 83 & 68 & 66 & 72 & 60 \\
\hline $\begin{array}{l}\text { Non-frameshift codon substitution } \\
\text { plus Insertion }\end{array}$ & 61 & 77 & 61 & 58 & 73 & 80 & 88 & 70 & 75 & 55 & 84 \\
\hline $\begin{array}{l}\text { Non-frameshift codon substitution } \\
\text { plus Deletion }\end{array}$ & 28 & 28 & 35 & 25 & 33 & 34 & 30 & 38 & 25 & 23 & 26 \\
\hline Stopgain & 4 & 14 & 10 & 4 & 9 & 5 & 7 & 9 & 9 & 10 & 12 \\
\hline Stoploss & 1 & 1 & 0 & 0 & 1 & 2 & 2 & 1 & 1 & 1 & 1 \\
\hline Startloss & 0 & 1 & 0 & 0 & 2 & 0 & 2 & 1 & 0 & 1 & 1 \\
\hline Exonic & 689 & 777 & 754 & 702 & 772 & 869 & 832 & 754 & 782 & 715 & 751 \\
\hline Splicing & 62 & 58 & 57 & 59 & 62 & 60 & 60 & 63 & 61 & 57 & 66 \\
\hline NcRNA & 238 & 229 & 240 & 235 & 233 & 249 & 259 & 239 & 223 & 222 & 248 \\
\hline UTR5 & 178 & 194 & 188 & 180 & 186 & 198 & 216 & 174 & 172 & 174 & 203 \\
\hline UTR3 & 1530 & 1510 & 1427 & 1276 & 1498 & 1471 & 1797 & 1372 & 1414 & 1382 & 1519 \\
\hline Intronic & 11,915 & 11,636 & 11,562 & 10,061 & 11,403 & 11,572 & 13,936 & 10,245 & 10,997 & 10,788 & 11,579 \\
\hline Upstream & 283 & 280 & 307 & 266 & 304 & 293 & 338 & 242 & 279 & 239 & 284 \\
\hline Downstream & 733 & 710 & 683 & 603 & 740 & 708 & 846 & 663 & 682 & 688 & 738 \\
\hline Intergenic & 302 & 296 & 271 & 241 & 250 & 258 & 329 & 276 & 263 & 255 & 269 \\
\hline \multicolumn{12}{|l|}{ SNP analysis } \\
\hline Total & 134,311 & 134,225 & 136,378 & 129,878 & 134,039 & 133,761 & 166,869 & 127,698 & 130,216 & 131,224 & 134,002 \\
\hline 1000genome and dbsnp & 121,404 & 120,889 & 122,334 & 116,489 & 120,656 & 119,805 & 152,022 & 114,903 & 117,222 & 117,467 & 119,890 \\
\hline 1000genome specific & 443 & 456 & 451 & 450 & 466 & 500 & 503 & 473 & 473 & 443 & 436 \\
\hline dbSNP specific & 4979 & 5030 & 5142 & 4963 & 5008 & 5188 & 5533 & 4875 & 5051 & 5034 & 5008 \\
\hline dbSNP rate & $94.10 \%$ & $93.81 \%$ & $93.47 \%$ & $93.51 \%$ & $93.75 \%$ & $93.45 \%$ & $94.42 \%$ & $93.80 \%$ & $93.90 \%$ & $93.35 \%$ & $93.21 \%$ \\
\hline Novel & 7485 & 7850 & 8451 & 7976 & 7909 & 8268 & 8811 & 7447 & 7470 & 8280 & 8668 \\
\hline Homozygous & 51,982 & 53,569 & 52,947 & 51,462 & 51,793 & 50,013 & 32,944 & 48,638 & 50,529 & 51,424 & 51,815 \\
\hline Heterozygous & 82,329 & 80,656 & 83,431 & 78,416 & 82,246 & 83,748 & 133,925 & 79,060 & 79,687 & 79,800 & 82,187 \\
\hline Synonymous & 11,043 & 11,075 & 11,209 & 10,961 & 10,967 & 11,123 & 14,116 & 11,169 & 11,048 & 11,104 & 11,215 \\
\hline Missense & 10,750 & 10,857 & 10,991 & 10,820 & 10,768 & 11,029 & 13,713 & 10,878 & 10,892 & 10,768 & 10,992 \\
\hline Stopgain & 100 & 113 & 117 & 110 & 102 & 109 & 139 & 113 & 111 & 117 & 113 \\
\hline Stoploss & 30 & 33 & 31 & 30 & 28 & 35 & 34 & 33 & 31 & 35 & 27 \\
\hline Startgain & 506 & 509 & 496 & 468 & 524 & 491 & 639 & 466 & 487 & 495 & 503 \\
\hline Startloss & 30 & 29 & 26 & 27 & 30 & 30 & 36 & 24 & 29 & 30 & 32 \\
\hline Exonic & 21,979 & 22,126 & 22,390 & 21,970 & 21,916 & 22,346 & 28,067 & 22,241 & 22,131 & 22,075 & 22,402 \\
\hline Splicing & 159 & 162 & 166 & 149 & 150 & 156 & 191 & 168 & 157 & 157 & 158 \\
\hline
\end{tabular}


Table 2 Variations identified by whole exome sequencing (Continued)

\begin{tabular}{llllllllllll}
\hline NCRNA & 3252 & 3279 & 3410 & 3233 & 3381 & 3329 & 3809 & 3283 & 3281 & 3245 & 3284 \\
UTR5 & 1981 & 2028 & 2080 & 1993 & 2015 & 2096 & 2498 & 1908 & 1948 & 1968 & 2061 \\
UTR3 & 7707 & 7707 & 7821 & 7485 & 7825 & 7652 & 9778 & 7461 & 7527 & 7610 & 7820 \\
Intronic & 89,844 & 89,674 & 91,108 & 86,065 & 89,445 & 88,742 & 111,479 & 83,963 & 86,127 & 87,172 & 89,093 \\
Upstream & 2248 & 2299 & 2339 & 2195 & 2262 & 2344 & 2743 & 2040 & 2170 & 2152 & 2237 \\
Downstream & 4596 & 4483 & 4540 & 4325 & 4523 & 4471 & 5408 & 4202 & 4364 & 4429 & 4516 \\
Intergenic & 2545 & 2467 & 2524 & 2463 & 2522 & 2625 & 2896 & 2432 & 2511 & 2416 & 2431 \\
SIFT & 1859 & 1905 & 1934 & 1819 & 1833 & 1939 & 2556 & 1918 & 1866 & 1892 & 1904 \\
\hline
\end{tabular}

the formation of isolate cataract [21, 22], including crystallins, such as $\alpha-, \beta-, \gamma$-crystallins (e.g., CRYAA, CRYBB1, $C R Y B B 2, C R Y G D)$, membrane transport and channel proteins, such as $\alpha$-connexins (GJA3, GJA8).

Intercellular gap junction channels provide pathways for metabolic and electrical coupling between cells in different tissues, and they are permeable to ions and small solutes, such as ions $(\mathrm{K}+, \mathrm{Ca} 2+)$, nutrients and small metabolites [23]. Gap junction channels consist of connexin protein subunits. Connexin proteins also known as gap junction proteins have four transmembrane domins with two extracellular loops (E1 and E2) and three intracellular regions (the NH2-terminus, a cytoplasmic loop and the COOH-terminus) [24]. Three isoforms of the connexin gene family- $C x 43$ (GJA1), $C x 46$ (GJA3) and $C x 50$ (GJA8) are abundantly expressed in the vertebrate lens.

C $x 50$ is an important protein and play an important role during lens growth, maturation of lens fiber cells, and lens transparency [25]. Cx50 comprises two exons with exon-2 coding for the entire 433 amino acid

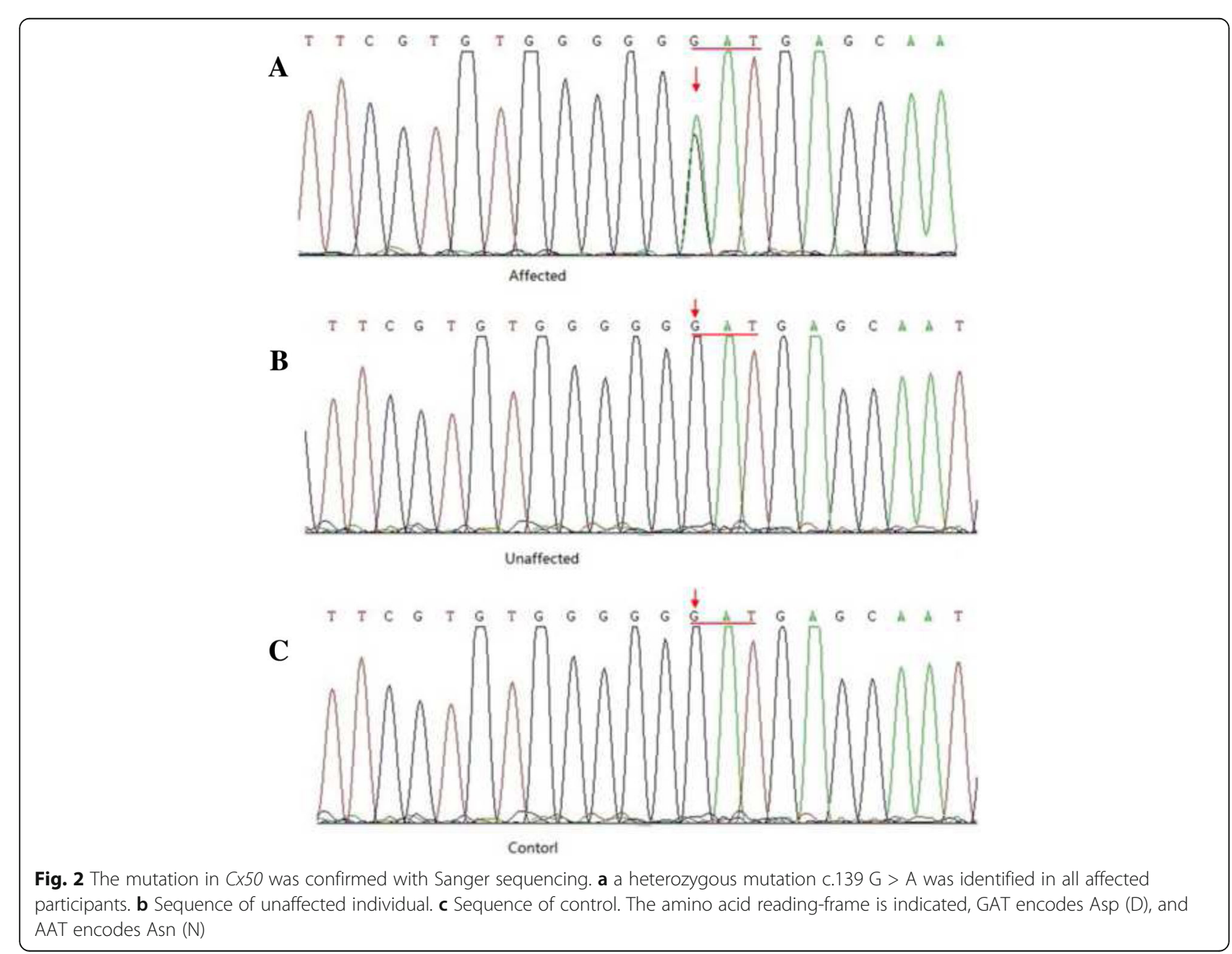




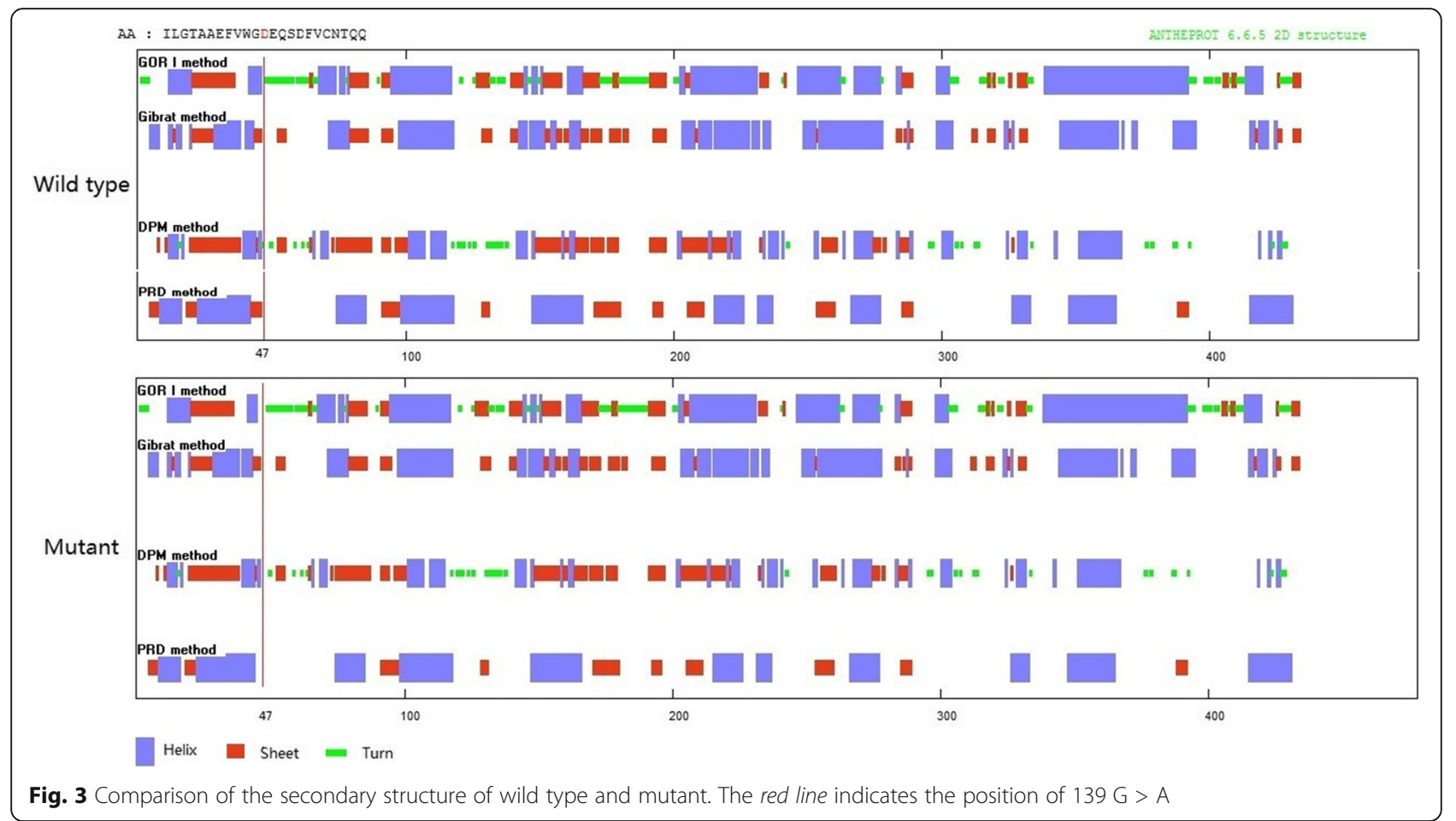

residues of gap junction protein $\alpha 8$ (GJA8). Up to date, at least 32 mutations in $C \times 50$ have been identified to contribute to cataract. Of the 32 coding mutations, 29 result in missense substitutions that are involved in autosomal dominant cataract, and two are frameshift mutation associated with autosomal recessive cataract [6]. The majority of missense substitution are situated in the N-terminal half of the protein, which also contains the conserved connexin domain (amino acids 3-109) [6]. Three types of mutation: $\mathrm{D} 47 \mathrm{~N}, \mathrm{D} 47 \mathrm{H}$ and $\mathrm{D} 47 \mathrm{Y}$ indicate that the amino acid at position 47 in GJA8 is a mutational hot spot [26-28]. Functional findings showed that D47N mutant expressed in Xenopus oocyte pairs could not form functional gap junction channels. Moreover, co-expression of Cx50D47N with wild-type Cx50 did not inhibit the activity of wild-type Cx50 [29]. The similar behavior was also observed in the mouse Cx50D47A, a mutation underlying the cataracts in the No2 mouse [30]. D47N and D47A mutants were loss-of-function mutants. Cellular level studies showed that the mutation of Cx50 prevented its localization to the plasma membrane. And this may lead to a capacity deficiency of Connexin 50, triggering a complex sequence of events, such as disruption of transmembrane ion gradients, loss of membrane potential, decreased cell growth and subsequent decreased metabolic activity [25, 31]. Cx50 is critical for balland-socket structures, actin distribution and fiber cell morphology. Cx50 gap junctional communication through ball-and-socket is important for lens development, especially during rapid, early fiber cell growth [32].

Some limitations of this study should be addressed. First, we did not collect all of pedigree samples, especially the affected individuals in the congenital cataract family. Secondly, we did not perform more experiments,
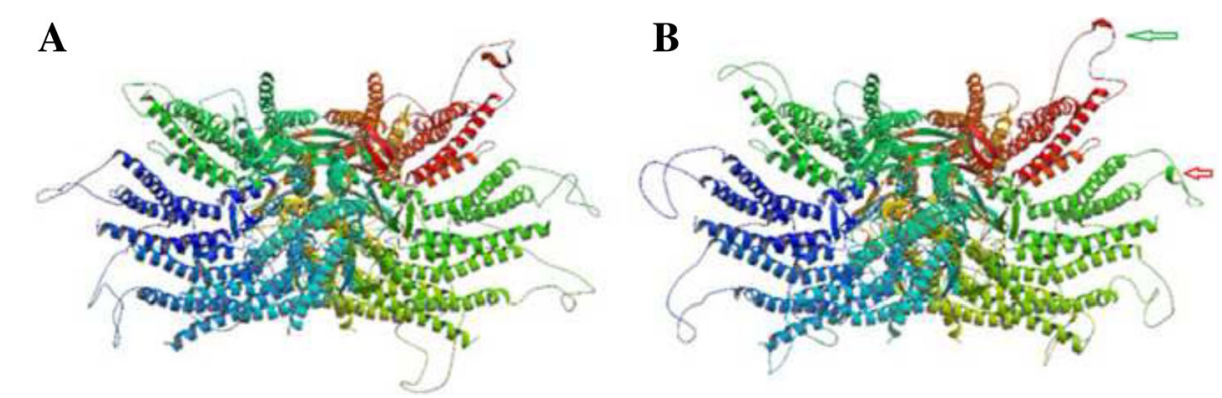

Fig. 4 Structure homology modeling and comparison of muant protein and wild type Cx 50. a Wild type Cx50. b Mutant protein Cx50 
such as cell function experiment of D47N mutant and animal model experiments. Both of these limit our knowledge of more information of the $\mathrm{D} 47 \mathrm{~N}$ mutant. Nonetheless, advantages in our study should also be acknowledged. Exome sequencing and next-generation sequencing provide a rational approach to screen all candidate genes for inherited cataract or other inherited disease. In addition, exome sequencing and next-generation sequencing are suitable for molecular diagnosis of hereditary diseases. Our finding supports the enormous potential of exome sequencing in molecular diagnosis of single gene disease.

\section{Conclusions}

In conclusion, the present research confirmed a recurrent mutation, c.139 G > A (p.D47N) in Cx50 in a six-generation Chinese family with autosomal dominant congenital cataract. This result provided further evidence for $C x 50$ in association with congenital cataract, and the amino acid at position 47 is a mutational hotspot. The function of $\mathrm{D} 47 \mathrm{~N}$ mutation needs to be further certificated in animal mode. In addition, exome sequencing and next-generation sequencing are suitable for molecular diagnosis of hereditary diseases.

\section{Abbreviations}

CRYAA: Crystallin Alpha A; CRYAB: Crystallin Alpha B; CRYBA1: Crystallin Beta A1; CRYBA3: Crystallin Beta A3; CRYBA4: Crystallin Beta A4; CRYBB1: Crystallin Beta B1; CRYBB2: Crystallin Beta B2; CRYBB3: Crystallin Beta B3;

CRYGA: Crystallin Gamma A; CRYGC: Crystallin Gamma C; CRYGD: Crystallin Gamma D; CRYGS: Crystallin Gamma S; Cx43: Connexin43; Cx46: Connexin46; Cx50: Connexin50; GJA1: Gap Junction Protein Alpha 1; GJA3: Gap Junction Protein Alpha 3; GJA8: Gap Junction Protein Alpha 8

\section{Acknowledgments}

We thank all participants including healthy control peoples, patients and their families in this study. We also thank all the people who helped us to complete the research successfully.

\section{Consent for publication}

Informed written consent was obtained from all participants of the family. If the participants are children (under 16 years of age), the informed consent was signed by their parents.

\section{Funding}

This work was supported by a grant from Daqing Oil Field Innovation Fund (No.2015018).

\section{Availability of data and materials}

The datasets in the current study are available from the corresponding author on reasonable request.

\section{Authors' contributions}

CS, HM and XC conceived and designed the experiments; CS, JW, XW, and FW performed the experiments; $C S, J W, X G, Y C, Y L$, and $L Z$ analyzed the data; HM contributed reagents/materials/analysis tools; CS wrote the paper; All authors have read and approved the final manuscript.

\section{Competing interests}

The authors announce that they have no affiliations with or involvement in any organization or entity with any financial interest, or non-financial interest in the materials or subject matter discussed in this paper.

\section{Ethics approval and consent to participate}

This research was approved by the ethics committee of General Hospital of Daqing Oil Field and was conducted according to the Declaration of Helsinki of the World Medical Association. Informed written consent was obtained from the participants or their legal guardians (if the participant was underage).

\section{Publisher's Note}

Springer Nature remains neutral with regard to jurisdictional claims in published maps and institutional affiliations.

\section{Author details}

'Department of Clinical Diagnosis, General Hospital of Daqing Oil Field, Daqing, Heilongjiang Province, People's Republic of China. ${ }^{2}$ Department of Ophthalmology, General Hospital of Daqing Oil Field, Daqing, Heilongjiang Province, People's Republic of China.

Received: 22 September 2016 Accepted: 15 May 2017

Published online: 19 May 2017

\section{References}

1. Apple DJ, Ram J, Foster A, Peng Q. Elimination of cataract blindness: a global perspective entering the new millenium. Surv Ophthalmol. 2000; 45(Suppl 1):S1-196.

2. Holmes JM, Leske DA, Burke JP, Hodge DO. Birth prevalence of visually significant infantile cataract in a defined U.S. population. Ophthalmic Epidemiol. 2003;10(2):67-74.

3. Francis PJ, Berry V, Bhattacharya SS, Moore AT. The genetics of childhood cataract. J Med Genet. 2000;37(7):481-8.

4. Reddy MA, Francis PJ, Berry V, Bhattacharya SS, Moore AT. Molecular genetic basis of inherited cataract and associated phenotypes. Surv Ophthalmol. 2004;49(3):300-15

5. Hejtmancik JF. Congenital cataracts and their molecular genetics. Semin Cell Dev Biol. 2008;19(2):134-49.

6. Mackay DS, Bennett TM, Culican SM, Shiels A. Exome sequencing identifies novel and recurrent mutations in GJA8 and CRYGD associated with inherited cataract. Hum Genomics. 2014:8:19.

7. Santana A, Waiswo M. The genetic and molecular basis of congenital cataract. Arq Bras Oftalmol. 2011:74(2):136-42.

8. Arora A, Minogue PJ, Liu X, Reddy MA, Ainsworth JR, Bhattacharya SS, Webster AR, Hunt DM, Ebihara L, Moore AT, Beyer EC, Berthoud VM. A novel GJA8 mutation is associated with autosomal dominant lamellar pulverulent cataract: further evidence for gap junction dysfunction in human cataract. J Med Genet. 2006;43(1):e2

9. Ge XL, Zhang Y, Wu Y, Lv J, Zhang W, Jin ZB, Qu J, Gu F. Identification of a novel GJA8 (Cx50) point mutation causes human dominant congenital cataracts. Sci Rep. 2014;4:4121.

10. Kaul H, Riazuddin SA, Shahid M, Kousar S, Butt NH, Zafar AU, Khan SN, Husnain T, Akram J, Hejtmancik JF, Riazuddin S. Autosomal recessive congenital cataract linked to EPHA2 in a consanguineous Pakistani family. Mol Vis. 2010;16:511-7.

11. Shiels A, Bennett TM, Knopf HL, Maraini G, Li A, Jiao X, Hejtmancik JF. The EPHA2 gene is associated with cataracts linked to chromosome $1 \mathrm{p}$. Mol Vis. 2008;14:2042-55.

12. Shiels A, Bennett TM, Knopf HL, Yamada K, Yoshiura K, Niikawa N, Shim S, Hanson PI. CHMP4B, a novel gene for autosomal dominant cataracts linked to chromosome 20q. Am J Hum Genet. 2007:81(3):596-606.

13. Su D, Yang Z, Li Q, Guan L, Zhang H, Dandan E, Zhang L, Zhu S, Ma X. Identification and functional analysis of GJA8 mutation in a Chinese family with autosomal dominant perinuclear cataracts. PLoS One. 2013;8(3):e59926.

14. Wang K, Wang B, Wang J, Zhou S, Yun B, Suo P, Cheng J, Ma X, Zhu S. A novel GJA8 mutation (p.I31T) causing autosomal dominant congenital cataract in a Chinese family. Mol Vis. 2009;15:2813-20.

15. Li H, Durbin R. Fast and accurate short read alignment with Burrows-Wheeler transform. Bioinformatics. 2009;25(14):1754-60.

16. McKenna A, Hanna M, Banks E, Sivachenko A, Cibulskis K, Kernytsky A, Garimella K, Altshuler D, Gabriel S, Daly M, DePristo MA. The genome analysis toolkit: a MapReduce framework for analyzing next-generation DNA sequencing data. Genome Res. 2010;20(9):1297-303. 
17. Arnold K, Bordoli L, Kopp J, Schwede T. The SWISS-MODEL workspace: a web-based environment for protein structure homology modelling. Bioinformatics. 2006;22(2):195-201.

18. Churchill A, Graw J. Clinical and experimental advances in congenital and paediatric cataracts. Philos Trans R Soc Lond Ser B Biol Sci. 2011; 366(1568):1234-49.

19. Huang B, He W. Molecular characteristics of inherited congenital cataracts. Eur J Med Genet. 2010;53(6):347-57.

20. Yi J, Yun J, Li ZK, Xu CT, Pan BR. Epidemiology and molecular genetics of congenital cataracts. Int J Ophthalmol. 2014;4(4):422-32.

21. Shiels A, Bennett TM, Hejtmancik JF. Cat-map: putting cataract on the map. Mol Vis. 2010;16:2007-15.

22. Shiels A, Hejtmancik JF. Genetics of human cataract. Clin Genet. 2013;84(2):120-7.

23. Beyer EC, Berthoud VM. Connexin hemichannels in the lens. Front Physiol. 2014;5:20

24. Yeager M, Harris AL. Gap junction channel structure in the early $21 \mathrm{st}$ century: facts and fantasies. Curr Opin Cell Biol. 2007;19(5):521-8.

25. Sellitto C, Li L, White TW. Connexin50 is essential for normal postnatal lens cell proliferation. Invest Ophthalmol Vis Sci. 2004;45(9):3196-202.

26. Li J, Wang Q, Fu Q, Zhu Y, Zhai Y, Yu Y, Zhang K, Yao K. A novel connexin 50 gene (gap junction protein, alpha 8) mutation associated with congenital nuclear and zonular pulverulent cataract. Mol Vis. 2013;19:767-74.

27. Lin Y, Liu NN, Lei CT, Fan YC, Liu XQ, Yang Y, Wang JF, Liu B, Yang ZL. A novel GJA8 mutation in a Chinese family with autosomal dominant congenital cataract. Zhonghua Yi Xue Yi Chuan Xue Za Zhi. 2008;25(1):59-62.

28. Wang L, Luo Y, Wen W, Zhang S, Lu Y. Another evidence for a D47N mutation in GJA8 associated with autosomal dominant congenital cataract. Mol Vis. 2011;17:2380-5.

29. Arora A, Minogue PJ, Liu X, Addison PK, Russel-Eggitt I, Webster AR, Hunt DM, Ebihara L, Beyer EC, Berthoud VM, Moore AT. A novel connexin50 mutation associated with congenital nuclear pulverulent cataracts. J Med Genet. 2008;45(3):155-60.

30. Steele EC Jr, Lyon MF, Favor J, Guillot PV, Boyd Y, Church RL. A mutation in the connexin $50(\mathrm{C} \times 50)$ gene is a candidate for the No2 mouse cataract. Curr Eye Res. 1998;17(9):883-9.

31. Minogue PJ, Tong JJ, Arora A, Russell-Eggitt I, Hunt DM, Moore AT, Ebihara $L$, Beyer EC, Berthoud VM. A mutant connexin50 with enhanced hemichannel function leads to cell death. Invest Ophthalmol Vis Sci. 2009; 50(12):5837-45.

32. Wang E, Geng A, Maniar AM, Mui BWH, Gong X. Connexin 50 regulates surface ball-and-socket structures and fiber cell organization. Invest Ophthalmol Vis Sci. 2016;57(7):3039-46.

\section{Submit your next manuscript to BioMed Central and we will help you at every step:}

- We accept pre-submission inquiries

- Our selector tool helps you to find the most relevant journal

- We provide round the clock customer support

- Convenient online submission

- Thorough peer review

- Inclusion in PubMed and all major indexing services

- Maximum visibility for your research

Submit your manuscript at www.biomedcentral.com/submit 